\title{
Imaging the atomic structure of activated carbon
}

Article

Accepted Version

Harris, P. J. F., Liu, Z. and Suenaga, K. (2008) Imaging the atomic structure of activated carbon. Journal of Physics:

Condensed Matter, 20 (36). 362201. ISSN 1361-648X doi: https://doi.org/10.1088/0953-8984/20/36/362201 Available at https://centaur.reading.ac.uk/24764/

It is advisable to refer to the publisher's version if you intend to cite from the work. See Guidance on citing.

To link to this article DOI: http://dx.doi.org/10.1088/0953-8984/20/36/362201

Publisher: Institute of Physics Publishing

All outputs in CentAUR are protected by Intellectual Property Rights law, including copyright law. Copyright and IPR is retained by the creators or other copyright holders. Terms and conditions for use of this material are defined in the End User Agreement.

\section{www.reading.ac.uk/centaur}

\section{CentAUR}

Central Archive at the University of Reading

Reading's research outputs online 


\section{Imaging the atomic structure of activated carbon}

Peter J.F. Harris ${ }^{*}$, Zheng Liu ${ }^{\dagger}$ and Kazu Suenaga ${ }^{\dagger \ddagger}$

"Centre for Advanced Microscopy, J.J. Thomson Physical Laboratory, University of Reading, Whiteknights, Reading RG6 6AF, UK.

${ }^{\dagger}$ Nanotube Research Center, National Institute of Advanced Industrial Science and Technology (AIST), Tsukuba 305-8565, Japan.

†To whom correspondence may be addressed. E-mail: p.j.f.harris@reading.ac.uk (P.J.F.H.); suenaga-kazu@aist.go.jp (K.S.)

The precise atomic structure of activated carbon is unknown, despite its huge commercial importance in the purification of air and water. Diffraction methods have been extensively applied to the study of microporous carbons, but cannot provide an unequivocal identification of their structure. Here we show that the structure of a commercial activated carbon can be imaged directly using aberration corrected transmission electron microscopy. Images are presented both of the as-produced carbon and of the carbon following heat- treatment at $2000^{\circ} \mathrm{C}$. In the $2000^{\circ} \mathrm{C}$ carbon clear evidence is found for the presence of pentagonal rings, suggesting that the carbons have a fullerene-related structure. Such a structure would help to explain the properties of activated carbon, and would also have important implications for the modelling of adsorption on microporous carbons.

Activated carbon is used on an enormous scale in gas and water purification, metal extraction, medicine and many other applications ${ }^{1}$. It is prepared from a variety of carbonaceous precursors, including coal, peat and nutshells which are carbonised and then "activated", either by oxidization with $\mathrm{CO}_{2}$ or steam, or by treatment with acids, bases or other chemicals. The resulting carbon can have a surface area of $1500 \mathrm{~m}^{2} \mathrm{~g}^{-1}$ or more, explaining its huge adsorptive capacity. Its precise atomic structure, however, is unknown.

The first serious attempt to understand the structure of carbons produced by the pyrolysis of organic materials was made by Rosalind Franklin in the $1950 \mathrm{~s}^{2}$. She showed that these carbons fall into two distinct classes, which she called graphitizing and non-graphitizing. 
The kind of carbon from which activated carbon is derived is non-graphitizing, meaning that it cannot be transformed into crystalline graphite even at temperatures of $3000^{\circ} \mathrm{C}$ and above. Franklin put forward a simple model of non-graphitizing carbon based on small graphitic crystallites joined together by cross-links, but did not explain the nature of these cross-links. A later idea was that the cross-links might consist of domains containing sp ${ }^{3}$ bonded atoms $s^{3,4}$, but this had to be discounted when neutron diffraction studies showed that non-graphitizing carbons consist entirely of $\mathrm{sp}^{2}$ atoms ${ }^{5}$. A much more recent suggestion $^{6-9}$ is that non-graphitizing carbon has a structure related to that of the fullerenes, in other words that it consists of curved fragments containing pentagons and other non-hexagonal rings in addition to hexagons, as illustrated in Fig. 1. Such a structure would explain the microporosity of the carbon, and many of its other properties. However, obtaining direct experimental support for this hypothesis is extraordinarily difficult. Both X-ray and neutron diffraction have been extensively applied to non-graphitizing carbons, and in some studies the diffraction data has been interpreted in terms of a structure containing non-hexagonal rings ${ }^{10,11}$. But definitive proof that the atoms are bonded in pentagonal or hexagonal rings cannot be obtained using diffraction methods.

Until relatively recently, imaging the atomic structure of carbons using transmission electron microscopy would also have been impossible, as the highest achievable resolution was greater than the $\mathrm{C}-\mathrm{C}$ bond length $(0.142 \mathrm{~nm})$. However, the development of aberration correctors has improved the resolution of TEM to the point where the direct imaging of carbon networks becomes possible. Ideally, such imaging should be carried out at a lower accelerating voltage than is normally used for high resolution TEM in order to avoid beam damage. In previous studies, a TEM with a post-specimen aberration corrector has been operated at $120 \mathrm{kV}$ to image the atomic structure of topological defects in carbon nanotubes $^{12}$ and of individual molecules inside nanotubes ${ }^{13,14}$. Here we apply this technique, for the first time, to a conventional carbon. The carbon we have chosen to study is the commercial activated carbon Norit GSX. We deliberately chose an activated carbon for study rather than an untreated non-graphitizing carbon because the activation process results in an "open" structure which is more amenable to imaging by HRTEM. Norit GSX is derived from peat, which is carbonised in an inert atmosphere at $500^{\circ} \mathrm{C}$. Activation involves treating with steam at approximately $1000^{\circ} \mathrm{C}$ and washing in $\mathrm{HCl}$. This produces a carbon with a surface area of $950 \mathrm{~m}^{2} \mathrm{~g}^{-1}$ and an average pore size of approximately $3 \mathrm{~nm}$. As well as the as-received carbon, samples heated in Ar to 
$2000^{\circ} \mathrm{C}$ were imaged.

Specimens were prepared for TEM by dispersing the carbon in iso-propyl alcohol, mixing ultrasonically and depositing onto holey carbon support films. Images showing the overall morphology of the carbons were recorded using the Reading University JEOL 2010 microscope, operated at $200 \mathrm{kV}$. Atomic resolution imaging was carried out using the Tsukuba JEOL 2010F instrument, operated at 120kV. This has a post-specimen aberration corrector (CEOS), giving a point resolution of better than $0.14 \mathrm{~nm}$ at $120 \mathrm{kV}$. The $C_{s}$ was set to a value in the range from 0.5 to $5 \mu \mathrm{m}$ in this work. Images were digitally recorded using a Gatan 894 CCD camera under a slightly under-focus condition $(\Delta f=-1$ to $-6 \mathrm{~nm})$.

Micrographs of typical areas of the as-received and $2000^{\circ} \mathrm{C}$ carbons are shown in Figs. 2 (a) and (b) respectively. The as-received carbon has a disordered and porous microstructure consisting mainly of tightly curled single carbon layers. In the $2000^{\circ} \mathrm{C}$ carbon, the structure is still disordered, but with larger pores, bounded by more perfect carbon layers.

Obtaining high quality atomic resolution images of the fresh carbon was extremely challenging, owing to its highly disordered structure. Nevertheless, a number of such images were recorded, and a typical example is shown in Fig. 3. At the edge of this fragment the individual rings of carbon atoms are resolved: the bright spots represent the centres of the rings. These bright spots do not form extended hexagonal arrays, which is consistent with the low crystallinity of the carbon. However, some hexagonally arranged groups of spots can be seen, as well as possible pentagonal arrangements. The images we have obtained of the fresh carbon are not yet of sufficient quality to justify comparisons with simulations based on models of the structure. Nevertheless, our results demonstrate for the first time that atomic level imaging of this kind of highly disordered carbon is possible.

Recording atomic resolution images of the $2000^{\circ} \mathrm{C}$-heated carbon was considerably easier than for the as-prepared carbon, due to the greater degree of crystallinity. As noted above, the effect of heat-treatment is to induce the growth of curved and faceted carbon sheets, which enclose much larger pores than in the fresh carbon. These sheets 
were frequently just a single layer thick, and in such cases images could be obtained which showed the true atomic structure. Two such images are shown in Fig. 4. In both images networks of hexagonal rings can clearly be seen. Quite often the rows of hexagonal rings observed in such images displayed some curvature; this effect can be seen in Fig. 4 (b). This distortion indicates that the particle has a curved surface, rather than flat facets.

In some areas of the $2000^{\circ} \mathrm{C}$ carbon there was clear evidence for the presence of fivemembered rings. Figure 5 (a) shows a small region in which at least two such rings are apparently present. The area enlarged in Fig. 5 (b) shows an arrangement of 5 bright spots surrounding a central spot. A good match was obtained with the simulated image in Fig. 5 (c), which was obtained from the structure in Fig. 5 (d) using a standard multislice procedure. Here, the pentagon is oriented approximately parallel to the plane of the image. A second area which contains a pentagonal structure is shown in Fig. 5 (e). In this case the central pentagonal ring is not visible, and we believe this is because the ring is tilted away from the plane of the image. Support for this comes from the reasonable match which can be seen between the image and the simulated image in Fig. 5 (f), obtained from the structure in Fig. 5 (g). We recognise that the agreement between the images and simulations shown here is not exact, but this is to be expected since we are not dealing with perfect crystalline structures, but with disordered materials. Thus, the curvature of the fragments of carbon will be affected by the morphology of the surrounding material, and may not be identical to the idealised structures used for the image simulations. Taking this into account, we believe that the agreement is sufficiently good to provide convincing evidence for the presence of pentagonal carbon rings.

In summary, we have shown for the first time that aberration-corrected TEM can be used to image the atomic structure of a conventional carbon material, specifically the commercial activated carbon Norit GSX. Atomic resolution images of both the asproduced carbon and of the carbon following heat-treatment at $2000^{\circ} \mathrm{C}$ have been recorded. Images of the fresh carbon contained evidence of hexagonal rings, and possibly non-hexagonal ones, but were difficult to interpret due to the highly disordered structure. The $2000^{\circ} \mathrm{C}$-heated carbon contained larger hexagonal networks which were much more readily imaged. There was also strong evidence in some of the images for the presence of pentagonal rings. The presence of pentagons in the heat-treated carbon 
strongly suggests that such rings were present in the original carbon. Once formed, pentagons tend to be kinetically "locked in" to a hexagonal lattice, since there is no easy mechanism for them to migrate. The effect of heat-treatment on the fresh carbon is apparently to increase the size of the hexagonal networks, while leaving many of the pentagons intact. Our results therefore support the idea, put forward more than ten years $\mathrm{ago}^{6,7}$ that this type of carbon has a fullerene-related structure. As already noted, such a structure would help to explain many of the properties of non-graphitizing carbons, such as their microporosity, hardness and resistance to graphitization. A structure containing pentagonal rings would be naturally porous, due to the curvature of the carbon layers, and would be relatively hard compared to other carbons, owing to the absence of parallel graphene layers. The structure would also be resistant to graphitization, since nonhexagonal rings are extremely stable. The idea that microporous carbons have a fullerene-like structure has important implications for the modelling of adsorption on such carbons. Traditionally, such modelling exercises have utilised structural models derived from graphite, in which all the atoms are in hexagonal rings (e.g. ref. 15). The carbon pores are then assumed to have a slit-like shape, confined by parallel planes. If the fullerene-like models are correct, these ideas may have to be modified. Indeed, theoretical studies have already been carried out which show that a model structure containing fullerene-related elements provides a better basis for understanding adsorption on activated carbon than the traditional models ${ }^{16,17}$.

\section{Acknowledgements}

This work is partially supported by CREST and Grant-in-Aid from MEXT(19054017). We thank Peter Campbell and Margriet Reimerink of Norit for helpful discussions. 


\section{References}

1. Marsh, H. \& Rodríguez-Reinoso, F. (2006) Activated Carbon (Elsevier, Oxford).

2. Franklin, R.E. (1951) Proc. Roy. Soc. A 209, 196-218.

3. Ergun, S. \& Tiensuu, V.H. (1959) Acta Cryst. 12, 1050-1051.

4. Ergun, S. \& Alexander, L.E. (1962) Nature 195, 765-767.

5. Mildner, D.F.R. \& Carpenter, J.M. (1982) J. Non-Cryst. Solids 47, 391-402.

6. Harris, P.J.F. \& Tsang, S.C. (1997) Philosophical Magazine A 76, 667-677.

7. Harris, P.J.F. (1997) International Materials Reviews 42, 206-218.

8. Harris, P.J.F., Burian, A. \& Duber, S. (2000) Philosophical Magazine Letters 80, 381-386.

9. Harris, P.J.F. (2005) Critical Reviews in Solid State and Material Sciences 30, 235253.

10. Zetterstrom, P., Urbonaite S., Lindberg F., Delaplane R.G., Leis J. \& Svensson G. (2005) Journal of Physics: Condensed Matter 17, 3509-3524.

11. Hawelek, L., Koloczek, J., Brodka, A., Dore, J. C., Honkimaeki, V. \& Burian, A. (2007) Philosophical Magazine 87, 4973-4986.

12. Suenaga, K., Wakabayashi, H., Koshino, M., Sato, Y., Urita, K. \& lijima, S. (2007) Nat. Nanotech. 2, 358-360.

13. Sato, Y., Suenaga, K., Okubo, S., Okazaki, T. \& lijima, S. (2007) Nano Lett. 7, 3704 -3708 .

14. Liu, Z., Yanagi, K., Suenaga, K., Kataura, H. \& lijima, S. (2007) Nat. Nanotech. 2, 422-425.

15. Thomson, K.T. \& Gubbins, K.E. (2000) Langmuir 16, 5761-5773.

16. Terzyk, A.P., Furmaniak, S., Gauden, P.A., Harris, P.J.F., Włoch, J. \& Kowalczyk, P. (2007) Journal of Physics: Condensed Matter 19, 406208.

17. Terzyk, A.P., Furmaniak, S., Harris, P.J.F., Gauden, P.A., Włoch, J., Kowalczyk, P. \& Rychlicki, G. (2007) Physical Chemistry Chemical Physics 9, 5919-5927. 


\section{Figure Captions}

Figure 1 Illustration of curved carbon fragments, containing pentagonal and heptagonal rings as well as hexagons.

Figure 2 Conventional HRTEM micrographs showing general appearance of (a) fresh activated carbon, (b) activated carbon following heat treatment at $2000^{\circ} \mathrm{C}$.

Figure 3 Aberration-corrected HRTEM micrograph of the fresh activated carbon.

Figure 4 Aberration-corrected micrographs of the $2000^{\circ} \mathrm{C}$-heated carbon.

Figure 5 (a) Aberration-corrected micrograph of small area of the $2000^{\circ} \mathrm{C}$-heated carbon. (b) Enlarged region showing pentagonal arrangement of spots. (c) Simulated image of structure shown in (d). (e) Second region showing pentagonal arrangement. (f) Simulated image of structure shown in (d). 

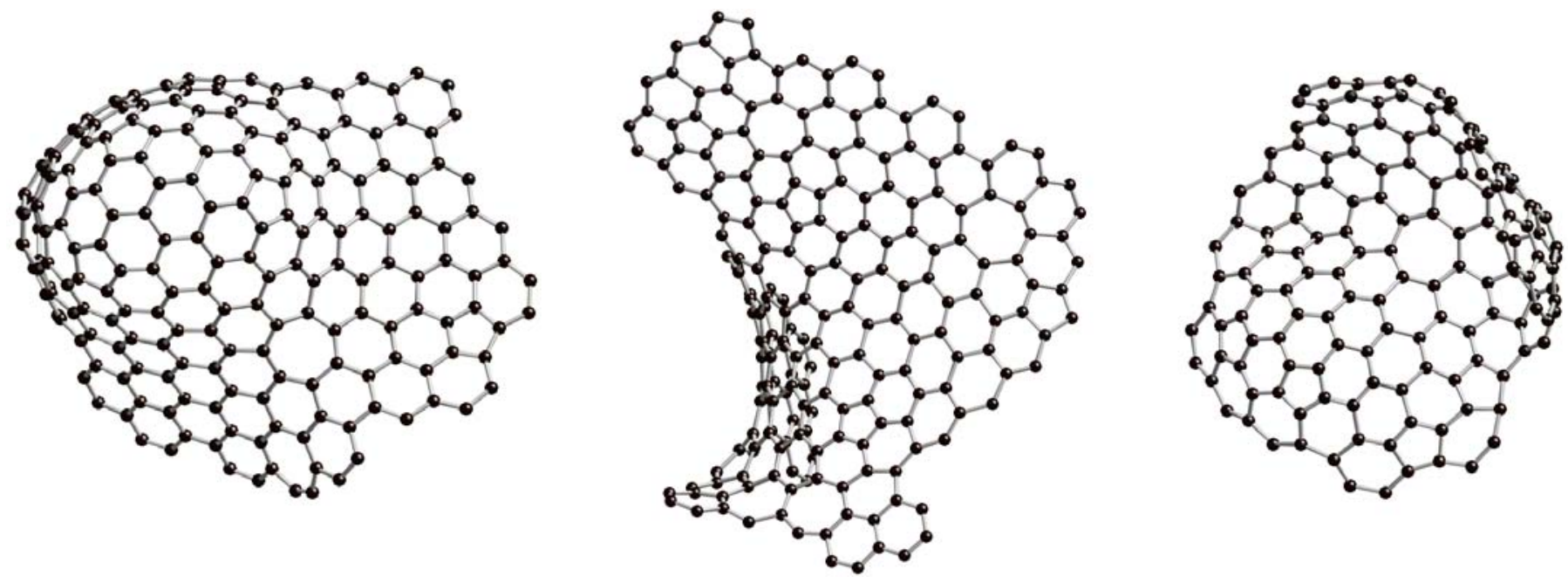

Figure 1 

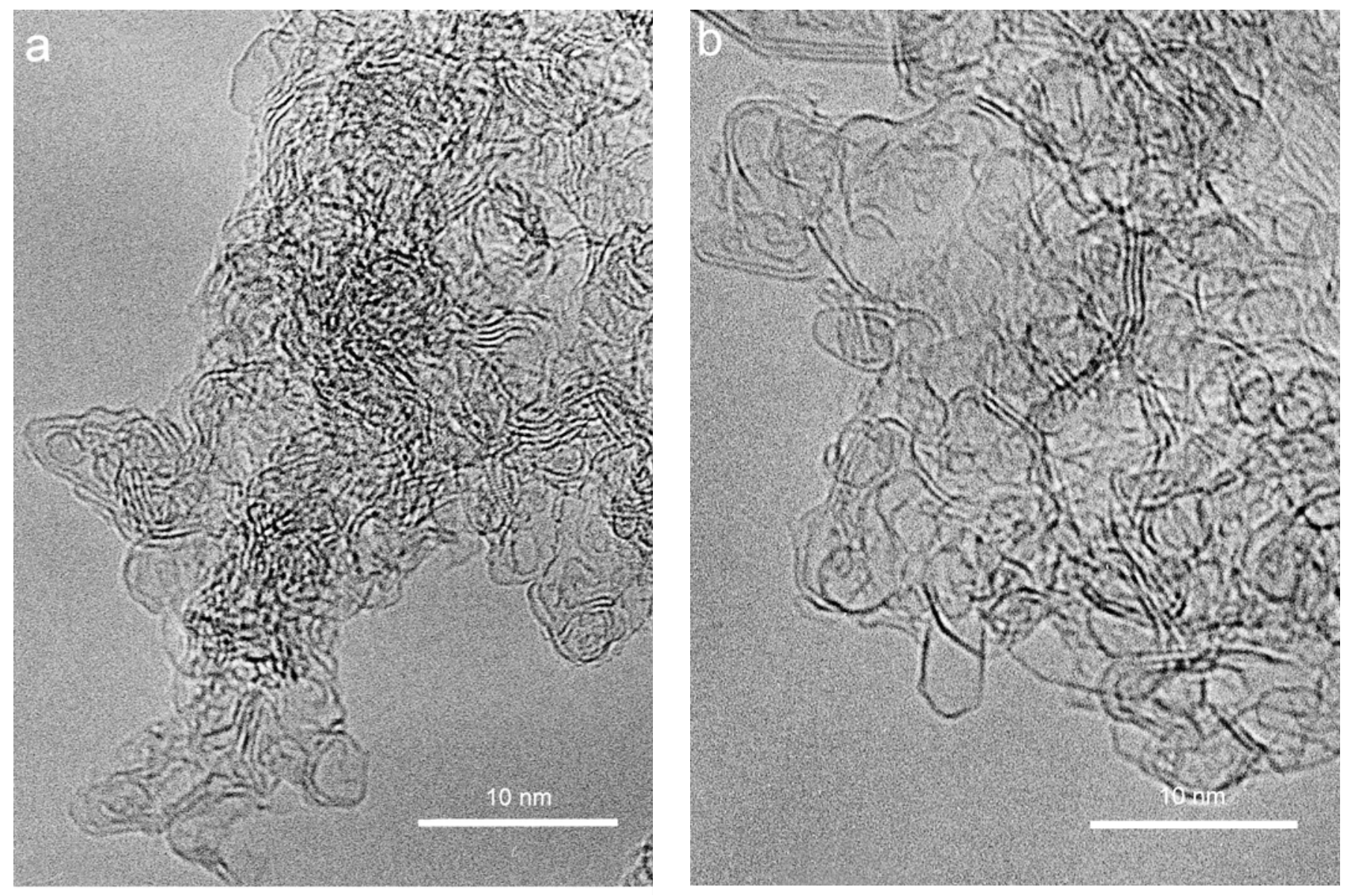

Figure 2 


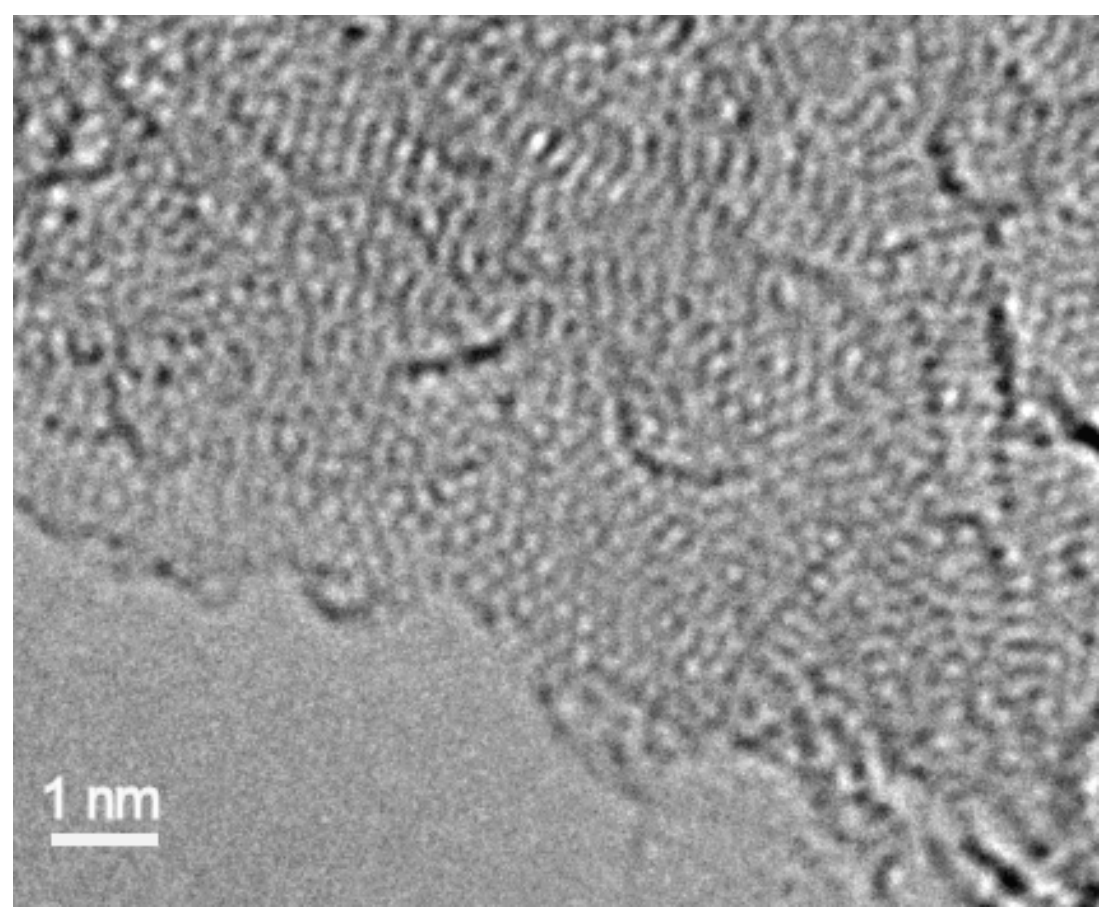

Figure 3 


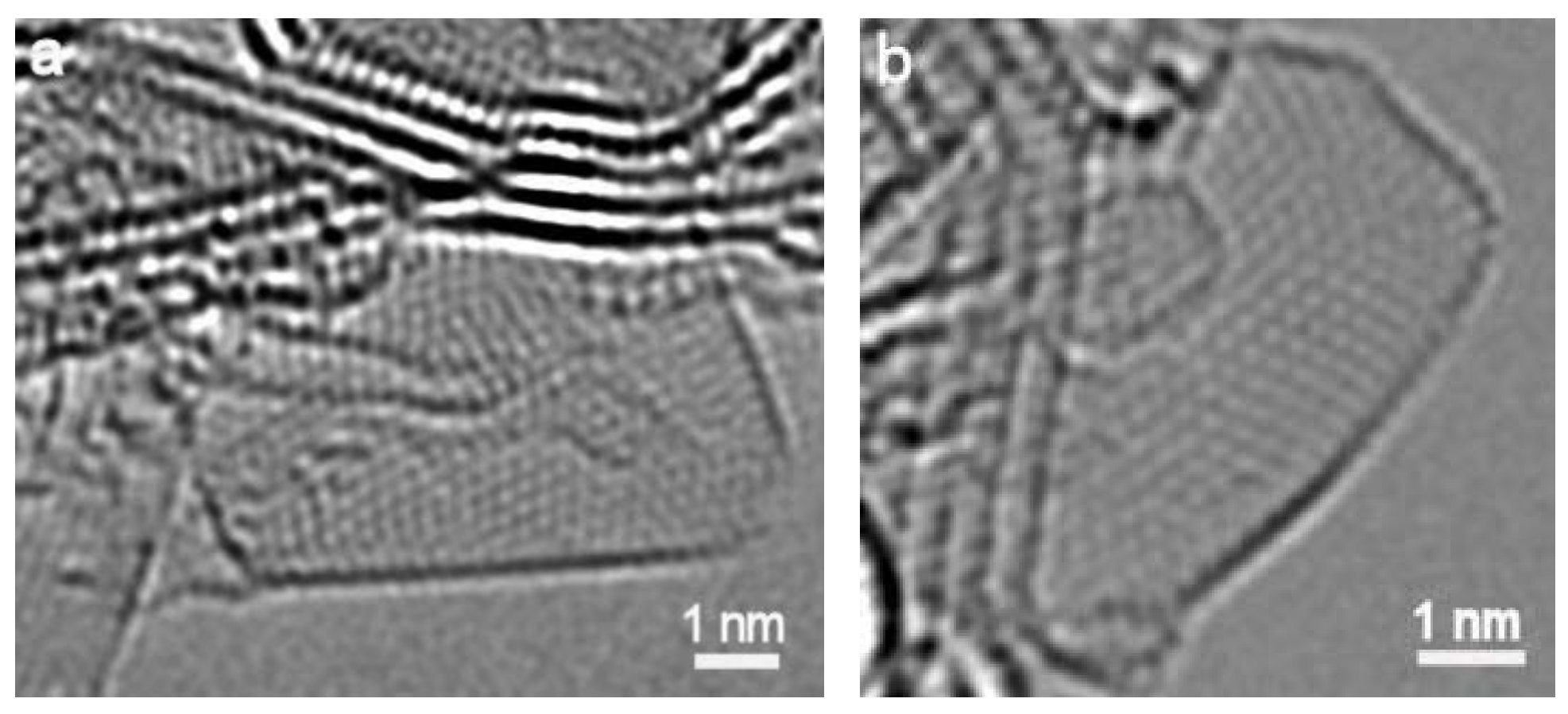

Figure 4 
a



Figure 5 